\title{
Focus issue on arrhythmias, echo and interventional cardiology
}

Li et al. from China and New Zealand evaluated electrocardiogram characteristics, echocardiographic parameters, cardiac functions, and the therapeutic effects of His bundle pacing in their review and meta-analysis. The results are worth looking at!

De la Pinta and Besse from Spain reviewed stereotactic ablative body radiotherapy for ventricular tachycardia: An alternative therapy for refractory patients. This is a new treatment modality for patients with ventricular tachycardia refractory to medical treatment and radiofrequency.

Karaca Özer et al. from Turkey studied the functional adaptations of the left ventricle (LV) in variant forms of left ventricular hypertrophy using conventional echocardiographic methods and two-dimensional speckle tracking echocardiography to determine the prognosis. Their article highlights the importance of the global longitudinal strain of LV.

Jia et al. from China discussed whether adding interleukin 6 biomarker to the CHA2DS2-VASc score could help determine the management of atrial fibrillation treatment.

In patients presenting with suspected unstable angina, speckle tracking echocardiography derived post-systolic shortening has reasonable sensitivity and good specificity in the diagnosis of obstructive coronary artery disease. This is the result of the study done by Giridharan et al. from India.

Gayretli Yayla et al. from Turkey compared Tp-e/QTc ratio with SYNTAX and GRACE score in patients undergoing coronary angiography because of acute coronary syndrome. Could this be a practical way of predicting arrhythmias?

One-year outcomes of the novel BioMime Morph tapered stent in long and multiple coronary artery lesions is the topic of Sharma et al.'s manuscript from India. They found it effective and safe.

Angiojet rheolytic thrombectomy (Possis Medical, Minneapolis, Minnesota) may be considered in patients with pulmonary emboli with multiple comorbidities and a tendency to bleed according to the results of a study by Akbal et al. from Turkey.

İbişoğlu et al. from Turkey tried to find an answer to "Long-term Results of Long Segment Coronary Artery Lesions Overlapped with Novolimus-Eluting DESolve Scaffold: Disappointment or Futuristic?" Their study throws up some intriguing results.

And of course, with plenty of new case reports, letters, and e-page originals.

I hope this issue will be of great interest to our readers.

Prof. Dr. Çetin EROL

Editor-in-Chief

Ankara-Turkey

Address for Correspondence: Prof. Dr. Çetin Erol,

Ankara Üniversitesi Tıp Fakültesi, İbn-i Sina Hastanesi, Kardiyoloji Anabilim Dalı, Ankara-Türkiye

Phone: +90 3123103333 /27 79 E-mail: ctnerol@yahoo.com

(C) Copyright 2021 by Turkish Society of Cardiology - Available online at www.anatoljcardiol.com

DOI:10.5152/AnatolJCardiol.2021.12 